a widely stretched area. These peritoneal-decidual scars are the ones most likely to rupture during pregnancy or labour from a rise in intra-uterine pressure.

\section{How Can Conditions be Improved?}

These conditions can be improved firstly by practising such measures as will prevent sepsis. The pelvis should be carefully examined some time before the commencement of labour, and if pelvic contraction or other deformity is found, appropriate treatment should be given. At the time of operation delivery of the placenta should be per vaginam to prevent the cervical portion of the membranes causing contamination. The uterus should be swabbed with an antiseptic lotion and then douched from above through the uterine incision, allowing the lotion to run out freely through the dilated cervix below. Careful uterine suturing during retraction, not during contraction, should be carried out. The material used for the sutures does not matter, the chief point is that the sutures should start well outside the edge of the incision, so as to include a good thickness of the uterine wall, except the decidua. After this layer is tied the peritoneal edges are accurately united. An alternative operation is the lower segment or cervical method which has lately been revived with a greatly improved technique; its chief exponent in this country is Prof. Munro Kerr. ${ }^{1}$

\section{TESTS OF RENAT EFFICIENCY.*}

\section{BY FRA N K KID, M.A., M.CH. CAMB.,} F.R.C.S. ENG.,

IATF SURGEON TO THE IONDON HOSPITAT; MEMBER OF THE INTERNATIONAL SOCIETY OF UROLOGY ; MEMBRE DE L'ASSOCIATION FRANÇAISE D'UROLOGIE.

Closely following the physiologists in the "seventies" and "eighties" of last century, the urinary surgeons searched for clinical tests of renal efficiency; they had urgent need for such tests, not only when considering nephrectomy and prostatectomy, but also when planning many other operations on the kidney or bladder. During the later years of last century, and in the first decade of the present century, Albarran and Kapsammer and their pupils were doing pioneer work in applying physiological knowledge to clinical purposes in order to find practical tests for estimating the power of the kidneys. These tests were, I believe, first introduced to English medicine in a book by Mr. Thomson Walker, "The Renal Function in Urinary Surgery" (1908) ; and in my book "Urinary Surgery" (1910) I passed in review the special renal tests then in use, and throughout the book pointed out how they should be employed in urinary surgery. Though some of us have employed these tests as routine measures for many years, the English profession as a whole has only lately wakened up to their importance-largely owing, I believe, to the prevalence of "trench nephritis" during the war.

Some of those who have taken up these tests in the last few years with enthusiasm have, I think, been led into confusion, because they have applied certain tests, fashionable at the moment, and have recorded them in great detail in their case records without much attempt to interpret the results; but it is of little use to apply tests unless you know how to interpret the results obtained, and also know on which to rely of all the numerous tests that have been placed on the theoretical market. Others have denied the benefit of prostatectomy to patients with poor functional renal tests, unaware that a two-stage operation can steer the way safely past kidneys depressed by back pressure.

* THE LANCET, 1920 , i., 1065 .
* paper based on a contribution to a discussion of Tests of Renal Function, held at the Section of Urology of the Troval Society of Mtedicine.
The Surgeon's Problems.

As regards tests of renal efficiency, the surgeon is particularly interested in two problems. (1) In considering prostatectomy to know if the kidneys are so. far destroyed by back pressure as to necessitate the carrying out of the operation in two stages. (2) In considering nephrectomy of one diseased kidney, to know if another kidney is present and fit to carry on if left by itself. In answering these questions renal function tests cannot stand by themselves; they must always be coördinated with all other clinical evidence available in any particular case.

A proof that these tests are of great value is that since their universal adoption by urinary surgeons the results of nephrectomy and prostatectomy have improved in a remarkable manner. The percentage mortality of nephrectomy has fallen from 40 per cent. in the latter end of last century to less than 2 per cent., and that of prostatectomy from 30 per cent. to less than 5 per cent. at the present day.

Classification of "Renal Efficiency" Tests.

Tests can be time tests pure and simple, or more elaborate quantitative tests. Time tests are found to be more reliable in practice than quantitative tests, and they are more easily carried out by the clinician.

\section{A. Excretion Tests.}

Applied to bodies excreted in the urine-time and quantitative tests.

1. No Artificial Stimulation.-Average daily quantity of water, colour, specific gravity, urea, chlorides, phosphates, albumin. Cryoscopy (Dreser 1892, Koranyi 1897) and index of refraction-measure of the molecular content of the urine. Measurement of electrical resistance (ionic content) after the method of Kohlrausch (Richter 1903, Dawson 'Turner 1906-07, Leyton 1912). Diastase (Wohlgemuth 1908-11), lactose, benzoic acid (1879).

2. Artificial Stimulation.-Time tests and quantitative tests applied by injecting certain substances into the tissues and noting their appearance in the urine. Dye-stuffs : Indigo-carmine (Heidenhain 1874, Voelcker and Joseph 1903); phenolsulphonephthalein (Rowntree and Geraghty 1910-12) ; methyleneblue (Casper 1892, obsolete because partially excreted as a colourless chromagen) ; fuchsin ; rosanilin, \&c. Drugs : Phloridzin-sugar (von Mehring 1882, Zuntz 1888); urea (Albarran 1905, McCaskey 1913-14, Pirondini 1914); iodides; salicylates, \&c. Water: Experimental polyuria (Albarran 1897-1903, giving excellent results but impracticable and unwise as ureteric catheters have to be left in situ for some hours). Alkalies and acids: Bicarbonate tolerancetest (Sellard).

\section{B. Retention Tests.}

Applied to excretory products retained in the blood, quantitative tests only: Urea and total nitrogen of blood; acidosis and artificial acidosis; chlorides (retention in many cedema cases and possible cause of œdema and high blood pressure in parenchymatous nephritis ; indican; toxicity of urine (Bouchard); cryoscopy (Koranyi 1897)-molecular content; electrical resistance-ionic content.

\section{Correlation Tests or Homorenal Indices.}

Comparisons made between the amount of substances in the blood and whole urine, or in the blood and the urines separated from each kidney: Urea (Ambard's constant); ions (electrical resistance method); molecules (cryoscopy); Wright's tests (hæmolysis).

The surgeon has a wide list from which to choose, and he needs a guide as to which tests are practical and which are not. My own experience leads me to advise that in the case of ureteric catheterisation he should rely chiefly on three tests-namely, a good dye test, indigo (which I prefer) or the phthalein test a good retention test-namely, the blood urea; and a good and simple correlation test-namely, the hæmorenal index as applied by the Kohlrausch electrical resistance method, which I have found of great use and easy to employ for oneself. In prostat- 
ectomy I advise a good dye test (indigo or phthalein), the blood-urea test, and the urea-concentration test. I may say at once that $I$ find the indigo test quite as satisfactory as the phthalein test, and shall continue to use it as my sheet anchor, in spite of all that has been alleged against it by the inventors of the phthalein test. The urea-concentration test, as far as I can determine, was first employed by Albarran in 1905.1 It appears to have been revived and restarted on a useful clinical career by McCaskey, of Fort Wayne, Indiana, ${ }^{2}$ and by Pirondini in Rome. ${ }^{3}$ Maclean states that he introduced the test, ${ }^{4}$ but $I$ do not feel convinced of this statement. It is due to MacLean's work that the test has become popularised.

\section{Prostatectomy.}

In prostatectomy the surgeon wishes to detect loss of function in both kidneys, considered together, as a result of back pressure before any of the ordinary clinical signs of back pressure have appeared. In such a case he has no need to separate the urines from each kidney before applying the tests. It is often forgotten that " surgical" uræmia from back pressure is entirely different from the " medical" uræmias ; for instance, œdema in "surgical" uræmia is seldom if ever seen except when there is concomitant heart failure. The early symptoms of "back-pressure" kidneys are headache and subnormal temperature, thirst, nausea, and occasional vomiting, hiccough, polyuria, persistent low specific gravity urine, high blood pressure, loss of weight, and pain in the back of the loins. If any or all of these signs are present then we know without special renal function tests that we are dealing with "back-pressure" kidneys, and the tests can only confirm our clinical findings. I find by experience, however, that in a large number of prostatic cases few if any of these signs are present, and yet the renal function tests may not be first-class, and may point to the need for an operation carried out in two stages. I have been performing prostatectomy in two stages in cases where the renal function tests are deficient for more than ten years, and have thereby been able to save by operation many patients who would otherwise have shortly succumbed to the dangers of catheter life.

\section{Dangers of Catheter Life.}

Catheter life may present little risk, though much inconvenience, to comparatively young prostatics who start upon it before the kidneys have become affected by back pressure; but experience tells me that if catheter life, or the "catheter operation" as I prefer to call it, is started after the kidneys have begun to fail, it is more dangerous than open operation done in two stages, and cannot prolong life as a successful two-stage operation can and does. In obvious cases with a giant atonic painless bladder and clear clinical signs of back pressure, on no account whatever should a catheter be passed for the purpose of carrying out tests. In such cases a catheter may kill in 48 hours. The only safe test to employ in such cases is an estimation of the blood urea. The bladder should simply be drained with a Pezzer tube, and the urethra left alone. Suprapubic drainage presents far less risk than catheter drainage. Tests can be carried out later through the Pezzer tube without passing a catheter.

\section{Procedure in Doubtful Cases.}

In doubtful cases I find "time tests" of great value and easy of execution. In doubtful cases only, without "giant" bladder, a catheter is passed and tied into the bladder and the urine is drawn off every quarter of an hour for one hour. I employ indigo-carmine and I expect a moderate degree of the blue to appear in the second specimen, and for a deep blue colouration to appear in the last two specimens. If this does not happen it is seldom if ever wise to operate in one

'Functional Diagnosis of Kidney Disease, Paris, 1905, p. 31, quoted by Mccaskey. Medical Record, 1914, March 21 st, p. 507.
J Journal d'Urologie, 1914, pp. 498, 499.

Modern Methods in the Diagnosis and Treatment of Renal Disease, 1921 , p. 53 . stage. The phthalein test is of equal value as a time test in these cases, but I doubt if its quantitative relations are of such accuracy as has been claimed by its orginators. A colorimeter to be read by the human eye can never give values of mathematical accuracy. In these cases the blood-urea test is also excellent; it does not show up as early, nor is it so delicate, as the dye tests, but it constitutes a good auxiliary test in doubtful cases. I have seen the blood-urea test become normal after drainage of the bladder long before the indigo test has returned to normal, and long before it is really safe to perform the second stage of the operation. In the majority of prostatic cases the kidneys regain sufficient functioning power after the first stage of the operation in 10 to 14 days to enable the second stage to be carried out; but in exceptional cases the kidneys may take four to six months to recover sufficiently. It is always wiser to wait too long than to operate too early.

To illustrate these remarks the following cases may be quoted :-

CASE 1.-Male, aged 60 , for a long time has passed water every half hour; no difficulty and no pain. For the last few months has had a little hæmaturia and pain at the end of the penis, a little pain in the lumbar region, and tremendous thirst. Rectal examination showed a very large prostate. Abdominal examination showed a giant painless bladder.

Operation.-Because of this, on clinical evidence alone no catheter was passed and no tests were done, but the bladder was opened and a Pezzer tube fixed in position.

The thirst disappeared in four days, the patient got up and felt perfectly well. At the end of ten days indigo tests were performed. No blue came through for over an hour. Patient was therefore sent home to wait until the kidneys recovered. He returned three weeks later. Indigo now came through in 15 minutes and there was a deep blue in 30 minutes. The prostate was shelled out; the patient healed up in three weeks, passed all his water naturally, and recovered his general health.

CASE 2.-Male, aged 57, two years' pain in hypogastrium difficulty in passing water, greatly increased frequency of micturition. Several attacks of acute retention, relieved by catheter. For the last week has been having a catheter passed regularly. Rectal examination showed a large adenomatous prostate. Urethroscopy showed no stricture. Edema of eyelids ; thirst. Catheter passed and tied in. Indigo injected into a muscle. No blue came through in the urine until $1 \frac{1}{4}$ hours had elapsed, and then only a faint tinge.

First Operation.--Oct. 7th, 1920, Pezzer tube fixed into bladder in suprapubic region. Indigo tests repeated weekly for some weeks showed little sign of improvement. Nov, 2nd, blood urea 0.086 per cent.; alkali reserve $60=$ normal. Ambard's index $0 \cdot 20$. Excretion of acid unimpaired. Patient up and about; had lost his thirst and felt perfectly well. Dec. 7 th, blood urea 0.096 per cent. (normal $=0.55$ per cent.), Ambard's index 0.24 (normal $=0.06$ per cent.). On the 16th urea-concentration test: First hour $120 \mathrm{c.cm}$. 1.8 per cent.; second hour $190 \mathrm{c.cm} ., 1.8$ per cent.; third hour $115 \mathrm{c.cm} ., 1.7$ per cent. Indigo test: A faint trace of blue comes through in three-quarters of an hour. Patient went back to business. Jan. 19th, 1921, indigo test gave same result as before. Feb. 15 th, indigo test: Blue came through in a quarter of an hour and a deep blue appeared in half an hour.

Second Operation.-Feb. 25th, a large prostate enucleated. Patient had healed up and was passing all his water naturally on the twenty-fourth day, and since then has had no further trouble.

This case illustrates very well the importance of performing the operation in two stages when the kidneys are not working properly. Though the patient was a comparatively young man, yet, when first seen, he presented definite clinical signs that the kidneys were not doing their work, and all the tests except the "alkali reserve" were bad. Within a fortnight of bladder drainage the patient felt as fit as ever he did in his life ; that is to say, all clinical signs of renal failure had disappeared, yet the tests were still very poor. As time went on all the tests got right except the indigo test, but I refused to operate until that test became normal When the indigo test became normal it did so quite suddenly, as is usually the case. The indigo test was the last test to become normal, which shows that it is the most sensitive and satisfactory test and the one that should be the chief 
guide when considering the time for the second stage of the operation on the prostate.

CAsE 3.-Male, aged 74. History of some months' difficulty in passing water, increased frequency, hæmaturia. Rectal examination showed a large adenomatous prostate; cystoscopy showed uric acid stones behind the prostate. Indigo came through in quarter of an hour, and in half an hour the urine was deeply blue. The urea was $34 \mathrm{mg}$. in $100 \mathrm{c.cm}$. of blood. Operation performed in one stage. Patient did well.

NEPHRECTOMY.-CATHETERISATION OF URETERS.

In considering the problem of nephrectomy tests must be applied to the urines separated from each kidney. Separators of the Luys and Cathelin type are dangerous and useless and should become obsolete. At the present day the urines should be separated by means of ureteric catheters; there are, however, certain important principles to be kept in mind in the practical application of these tests by means of ureteric catheters. These are as follows :-

1. There is no method yet arrived at by means of which the surgeon can be absolutely certain that he has collected all the urine in a given time from each kidney. Even if he empties the bladder at the beginning and end of the session he is still subjected to fallacies. For that reason alone $I$ doubt if any quantitative tests applied to ureteric catheter specimens are worth the trouble, as they are bound to lack accuracy.

2. The mere passage of a ureteric catheter upsets the quantitative renal balance for a time, varying in duration with the individual, and for each kidney but that passage does not upset the time-values. Ureteric catheterisation produces temporary anuria, oliguria, or polyuria in a degree which varies even in the two kidneys being tested, and influences the water more than the solids. Again we see that quantitative tests are likely to be fallacious, but fortunately the time-values are not upset. Some portion of the dye or drug injected will come through within 10 to 15 minutes if the kidney is healthy, unless reflex anuria is prolonged for more than this time, which it seldom if ever is.

3. Anæsthetics and fear of examination produce similar fallacies in the quantitative values.

4. Seeing, then, that quantitative tests as applied to ureteric catheter specimens are likely to be fallacious, and that it is very unwise to leave ureteric catheters in situ for more than a few mintues at a time (I cannot too strongly emphasise this point), I warn students not to apply quantitative tests which necessitate leaving ureteric catheters in place for an hour to several hours (urea-concentration test, experimental polyuria, \&c.). The prolonged in-dwelling of ureteric catheters sets up a ureteritis which may cause intense pain in, infection of, or damage to a previously healthy kidney.

5. Finally, disease of one kidney (especially neoplasm and hydronephrosis) may so depress the function of the other kidney that it is unwise always to refus6 nephrectomy simply because of doubtful functional tests. If the blood-urea is satisfactory, and if other clinical factors point the road, it is better to give the patient the benefit of the doubt if his disease of one kidney is likely to prove fatal without operation, and if there is reasonable evidence that another kidney is anatomically present and is not pathologically altered, even though it may not show up perfectly when considered functionally.

6. In certain cases of ureteric catheterisation, much time can be saved by injecting a drug or a dye intravenously rather than intramuscularly.

\section{Summary.}

To sum up, I would advise the following tests as of value in the case of ureteric catheterisation when considering nephrectomy :-

(a) Employ time tests pure and simple rather than quantitative tests. The time of the first appearance of indigo or phthalein is the important matter, not its amount. Time tests avoid the necessity for measuring the exact quantity of urine passed in a given time by each kidney. (b) Instantaneous simultaneous correlation tests applied to the blood and each urine may be of value in doubtful cases. I have found of considerable value the electrical resistance test applied to a drop of blood serum taken while the ureteric catheters are in situ and applied also to a drop of urine taken from each kidney at the same time. $\Lambda$ few drops of fluid only are required in this test, as compared with the large quantity needed for the cryoscopy and blood-urea hamorenal indices. This is why it is to be preferred in practice.

(c) The percentage of urea taken from the separated urines has often appeared to me of value, though in theory it should not be accurate. It is at any rate of more accuracy than attempts to measure the total quantity of urea passed in a certain time.

(d) Pathological and anatomical (pyelographic) considerations should not be forgotten; in practice the problem is usually solved satisfactorily by correlating them with functional considerations-e.g., does the urine from the poor kidney contain blood, pus, bacteria, as compared with the urine from the good kidney which is of good colour, free from pathological elements, and gives a good time test? Pyelography is a useful handmaid, concerning itself as it does with the surgical anatomy, and is often of more value than the tests which concern themselves with surgical physiology.

The chief uses of these ureteric catheter tests are in considering nephrectomy in cases of tuberculosis, neoplasm, stone, and hydronephrosis. If both kidneys are diseased (e.g., in tuberculosis), then the blood-urea test may be expected to warn us of this in cases of doubt. This is a fact well worth remembering.

Finally, I would rather put my trust in the indigo test than in all the other tests put together. It can be employed by the surgeon himself at the beside and is therefore superior to any laboratory test. I have used it for 15 years, and can recall only two or three instances in which it has failed me. Those were in cases of pyonephrosis on one side, where an alkalineinfected urine was also coming from the opposite kidney. In such cases the indigo may become decolorised in its passage through this infected kidney. Of course, I am excluding instances where the dye has not been injected properly into a muscle, or has not been properly prepared for injection-accidents that may happen unless the surgeon prepares and makes the injection himself.

\section{Medical Aspects.}

I would like to touch upon one or two points as regards these tests when applied to so-called medical cases. Many tests which act satisfactorily in surgical cases do not necessarily act at all in cases of medical nephritis, especially in parenchymatous nephritis, where the diseased kidneys appear to let through almost everything but the chlorides. The lack of correlation between damage to structure and damage to function has to be remembered in this connexion. Surgery is richer than medicine in the possession of evidence of damage to structure that can supplement the evidence of damage to function. In distinguishing between cardiac and renal disease the tests may be found to play a useful rôle. But in laying the founda tion for prognosis in medical cases I believe from experience that careful studies of the blood pressure will be found of great value, combined with estimations of the blood urea and with the urea-concentration test.

Ideal tests of renal efficiency should be as simple as possible, and such as can be carried out by the clinician himself. All tests should be put to the most searching scrutiny in combined work between the clinician and the laboratory worker. But in the end those should be chiefly adopted in practice which are found to be most accurate, and, above all, which should be capable of use by the clinician alone. That is why I prefer the dye tests to the diastase or the ureaconcentration test. Tests should be proved in the 
laboratory and then be put on the clinical market. You cannot in practice apply all possible tests to all cases, but you must know and practise a few good tests for routine use. I consider the indigo-carmine test the test par excellence; and in surgery $I$ believe that two classes of tests will survive the probation of time and experience-namely, the dye tests (indigo and phthalein), and the blood-urea and urea-concentration tests for prostatic and doubtful bilateral kidney disease.

Finally, no surgeon should operate on kidneys and prostates who has not had a good clinical training in the use of tests of renal efficiency. The risks taken even to-day by general surgeons who operate on such cases appal surgeons who have trained themselves in modern urological methods.

\section{A CASE OF}

\section{LARGE URACHAL CYST,}

\section{NOT COMMUNICATING WITH THE BLADDER.*}

\section{BY G. H. EDINGTON, D.Sc., C.M.,}

\section{F.R.F.P.S. GLAsG.,}

VISITING SURGEON, WESTERN INFIRMARY; LECTURER AND EXAMINER IN CLINICAL SURGERY, UNIVERSITY OF GLASGOW.

THE possible persistence in the urachus of allantoic remains is well enough known. It is met with in infancy as one of the forms of umbilical fistula, which may be " blind," or may be in communication with the urinary bladder. Another form of the abnormality sometimes seen post mortem is a nipple- or finger-like protrusion at the apex of the bladder. In a case ${ }^{1}$ of this sort a calculus may form and project into the cavity of the bladder; but the occurrence of the protrusion seems frequently unaccompanied by any clinical manifestations. The formation of a cyst may take place in the case of a protrusion having a very small communication with the bladder cavity; or, as in the case now reported, without any communication at all with that viscus.

This striking example of a cyst of the urachus was obtained from a farmer, aged 50, who consulted me in September, 1921, on account of an abdominal tumour of about two years' known duration.

History.-.His symptoms began two or three years previously as a sensation of tightness across the abdomen; later he experienced a feeling as of a heavy, "stone-like", weight in the right side. At this time his mouth used to run with water every day for two or three minutes, and this gave temporary relief from the feeling of weight in the right side. His appetite was good, and his bowels fairly regular. With his hands he could feel in the lower abdomen a swelling which gurgled on pressure. He had some delay in micturition.

On Examination.-Patient distinctly spare, but healthylooking. Lying on couch he presented in hypogastrium a visible bulge, cystic, dull on percussion, and freely mobile. Its mobility from side to side negatived my first impression that it was a distended bladder. No evidence of ascites; digital examination of rectum negative. The condition was looked upon as a tumour of the bladder, possibly malignant.

Operation.-Laparotomy was performed. When the patient had been anæsthetised, a catheter was passed with negative result. Transverse incision across the recti showed a large cyst filling up the pelvis and seated on the apex of the bladder. There were no adhesions, but the cyst could not easily be raised; it was dislodged only after a vertical incision down through the linea alba towards the pubes. The peritoneum was then cut across behind the pubes, and the extraperitoneal cyst was separated from the bladder wall after tying some large vessels passing to it from that organ. Its attachment to the bladder was very close, and great care was required in separating it from the vesical muscular coat. This was successfully accomplished without opening into the cavity of the bladder. The irregular wound of the peritoneum over the summit of the bladder was closed with difficulty, and the closure of the parietal peritoneum also was a little difficult; the other layers of the abdominal wall came together with ease.

* Communication to Royal Medico-Chirurgical Society of Glasgow.
Except that for the first week he required the catheter on account of retention, his recovery was uneventful, and he was discharged from the nursing home on the fourteenth dav after the operation.

The cyst was oval in outline, measuring $13 \mathrm{~cm}$. by $9 \mathrm{~cm}$., and its long axis was horizontal. It was completely invested by peritoneum, save at the area of its attachment to the bladder. Its contents were a clear, colourless, watery, and odourless fluid, having a specific gravity of below 1010 . It was examined by Mr. J. M. Johnston, who reported that it was faintly alkaline and non-albuminous, and gave a marked effervescence with sodium hypobromite. Its reaction to Fehling's solution was doubtful ; $\mathrm{HNO}_{3}$ brought down crystals of nitrate of urea; feathery crystals of phosphates were also obtained.

Histological Examination.-This examination of the cyst wall was made by Dr. A. S. Strachan, who showed it to consist almost entirely of fibrous tissue, with one or two intermingling strands of muscle fibre.

\section{Remarks.}

The literature, while perhaps not extensive, shows that considerable attention has been paid to the subject of urachal cysts. A very excellent paper was written in $1906 \mathrm{by}$ Weiser, ${ }^{2}$ and he refers to the analysis by Wutz, $^{3}$ in 1883 , of cases reported up till that time. Weiser tabulates no fewer than 58 cases in the literature between 1873 and 1904 , and 28 additional cases communicated to him by personal letter; and he himself publishes three, making 89 in all. His conclusions are that cysts are more common between the ages of 20 and 40 years. Under 15 years of age males and females are affected equally; in adult life females preponderate. In addition to the local signs of swelling the symptoms usually present are " a feeling of illness, loss of flesh, pain, often fever, gastric disturbance, and indeed the appearance of a tubercular subject", (loc. cit., p. 551). In a large proportion of these cases the cyst cannot be extirpated, on account of its relationships and adhesions to neighbouring viscera. In such cases irrigation and drainage have been resorted to with favourable results. Three years later, Doran 4 furnished a very good general account, with many bibliographical references. He refers to the microscopical characters of the urachus, and points out that if the cyst attains a considerable size the wall is correspondingly thinned out and loses some of the characteristic features of the urachal tube. (This, it may be observed, is common to large cysts of other regions and origins.) In default of characteristic histological features, however, Weiser (loc. cit.) considers that the extraperitoneal situation of the cyst, together with its attachment to the bladder, "makes the diagnosis conclusive." The unsuspected presence of a urachal cyst may have an important bearing on operative surgery. This is illustrated by a case reported in 1907 by Balfour Marshall, ${ }^{5}$ in which during the performance of a laparotomy an unrecognised cyst was opened, and as it communicated with the bladder the escape of urine suggested at first that that viscus had been wounded. Again, it is evident that the incising of a closed cyst might mislead the operator into thinking that he had entered the peritoneal cavity. In such a case he might reasonably feel temporarily confused.

In the case here reported the points to be noted are the history of digestive disturbance as evidenced by sialorrhoea relieving the feeling of weight; the very spare condition of the patient; and the slowness of micturition. As regards the cyst itself, although of large size, it had not formed any troublesome relationships with or attachments to any of the neighbouring viscera. Removal was therefore not only possible but comparatively easy.

Another interesting point is that, without there being any communication with the interior of the bladder, the fluid contained urea. The difficulty in bringing together at the close of the operation the irregularly divided peritoneum has been noted by other operators.

References.-1. Dykes, C.: THE LANCET, 1910, vol. i., p. 566. 2. Weiser : Annals of Surgery, vol. xliv. 1906, p. 529 . 3. Wutz: Tre THE LANCET, 1909, vol. i., p. 1304. 5. Mar 